\title{
Predictors of outcomes in COPD exacerbation cases presenting to the emergency department
}

\author{
N. Roche*, M. Zureik", D. Soussan ${ }^{\#}$, F. Neukirch" ${ }^{\#}$, D. Perrotin ${ }^{\star}$ and the Urgence \\ BPCO (COPD Emergency) Scientific Committee and investigators ${ }^{+}$
}

ABSTRACT: The aim of the present prospective multicentric study was to develop a simple rule for the prediction of poor outcome in patients presenting to emergency departments with initially non-life threatening-chronic obstructive pulmonary disease (COPD) exacerbations in a real-life setting.

All patients with an acute exacerbation of COPD visiting the emergency departments of 103 hospitals during a 3-month period were included, except those who immediately required intensive care unit admission and/or ventilatory support. The data collected included patient characteristics, in-hospital outcomes (mortality and length of stay) and mode of discharge (unsupported or need for post-hospital assistance).

The in-hospital mortality rate was $7.4 \%$ (59 out of 794 ). Independent prognostic factors were age, number of clinical signs of severity (among cyanosis, impaired neurological status, lower limb oedema, asterixis and use of accessory inspiratory or expiratory muscles) and dyspnoea grade in the stable state. The need for post-hospital support was also predicted by female sex. In order to construct and validate a prediction score for mortality based on these items, patients were randomly allocated to a derivation and a validation cohort. The prediction score showed good discrimination, with a c-statistic of 0.79 in the derivation cohort and 0.83 in the validation cohort.

Thus simple purely clinical factors can reliably predict the risk of death and requirement for post-hospital support in an initially non-life threatening-acute exacerbation of chronic obstructive pulmonary disease. Their use needs to be prospectively validated.

KEYWORDS: Chronic obstructive pulmonary disease, emergency department, exacerbation, outcome, prognosis

hronic obstructive pulmonary disease (COPD) is a major healthcare issue; its prevalence in the adult population ranges 4-10\%, and World Health Organization projections predict that COPD-related mortality and disability will continue to increase worldwide until at least 2030 [1]. Exacerbations are major events in the history of the disease, especially when hospitalisation is required. First, in-hospital mortality is high, although it varies markedly between studies (2.5$30 \%$ ), depending upon the mode of recruitment and setting (medical ward versus intensive care unit (ICU)) [2-6]. Secondly, exacerbations markedly impair quality of life [7], and their repetition may affect the natural history of the disease, as assessed by the rate of lung function decline $[8,9]$ and mortality [10]. Finally, they have a societal impact; although only $10-15 \%$ of COPD patients are hospitalised, they are responsible for more than half of COPD-related healthcare expenses, and, among respiratory diseases, COPD is the leading cause of direct medical costs [11-15]. Exacerbationrelated costs increase in the growing population of elderly subjects, who require post-hospital support more frequently [16].

Several studies have identified factors independently associated with in-hospital mortality due to COPD exacerbations, including nonrespiratory (especially cardiac) organ system dysfunction, duration of hospital stay, older age, comorbid conditions and nutritional status, arterial oxygen $\left(\mathrm{Pa}, \mathrm{O}_{2}\right)$ and carbon dioxide tension at entry, and requirement for ICU admission [4, 5, 17-22]. However, independent prognostic factors are quite variable between studies, probably related
AFFILIATIONS

${ }^{*}$ Respiratory and intensive care medicine, Hôtel-Dieu, Paris Descartes University, \# INSERM Unit 700, Paris 7 University, Paris,

"Intensive care medicine, Bretonneau Hospital, Tours University, Tours, France.

${ }^{+}$For a full list of the Scientific Committee, investigators and participating centres see the Acknowledgements section.

CORRESPONDENCE

N. Roche

Service de Pneumologie et

Réanimation

Hôpital de I' Hôtel Dieu

1, place du Parvis Notre-Dame

75004 Paris

France

Fax: 33142348448

E-mail: nicolas.roche@htd.aphp.fr

Received:

October 022007

Accepted after revision:

May 092008

\section{SUPPORT STATEMENT}

This study was supported by the Société de Pneumologie de Langue Française, SAMU de France, the Société Française de Médecine d'Urgence and INSERM Unit 700.

STATEMENT OF INTEREST Statements of interest for N. Roche, M. Zureik, F. Neukirch and D. Perrotin, and for the study itself can be found at www.erj.ersjournals.com/misc/ statements.shtm

European Respiratory Journa Print ISSN 0903-1936 Online ISSN 1399-3003 
to differences in patient populations, settings, duration of follow-up, variables collected and statistical methods. In addition, these studies did not specifically target patients visiting emergency departments (EDs), and, therefore, were not restricted to factors readily available in that environment. Thus it remains difficult to provide clinicians working in the emergency context with simple and reliable criteria for the identification of patients at risk of in-hospital death and help to decide whether or not the patient should be hospitalised and in which setting (medical ward or ICU).

Therefore, a real-life study was conducted in order to assess determinants of in-hospital outcomes in patients visiting EDs for COPD exacerbations. The outcomes considered were inhospital mortality and requirement for post-hospital support (either convalescence or nursing home or domiciliary support). A prediction score was built using a randomly selected subgroup of the study participants (derivation cohort) and tested in the other half of the recruited sample (validation cohort).

\section{MATERIALS AND METHODS}

The study protocol and case report form have already been published [23], along with supplementary online data. All procedures were approved by the ethics committee of Versailles hospital (Versailles, France) and by the institutional review boards of the scientific societies involved (the Société de Pneumologie de Langue Française, SAMU de France and the Société Française de Médecine d'Urgence), and informed consent was obtained from all of the patients.

\section{Study design}

Following a feasibility study in three centres, the present prospective observational study was conducted in 113 centres representative of French hospitals. The centres were asked to include all consecutive patients visiting their EDs between November 2003 and February 2004 with a diagnosis of certain or probable exacerbation of COPD at entry. Included patients were followed until discharge from hospital.

Since this was meant to be a real-life study, there was no constraint or guideline regarding investigations, admission and discharge decisions or treatments. In each centre, an emergency physician and a respiratory physician were in charge of quality control.

\section{Inclusion criteria}

Patients were included if they presented with a probable or certain exacerbation of COPD, as defined by the appearance or increase of dyspnoea in a patient with known COPD or risk factors for COPD (age $>40$ yrs and current or past cumulative tobacco consumption of $>10$ pack-yrs). Patients meeting these criteria were not included when the investigator judged that the predominant diagnosis was or was likely to be pulmonary embolism, congestive heart failure, pneumothorax or pleurisy, or when the predominant underlying respiratory disease was asthma, bronchiectasis, heart failure, thromboembolic disease or restrictive respiratory insufficiency. All of these exclusion criteria were left to the clinician's discretion in order to ensure that the real-life nature of the study was respected. Patients requiring immediate ICU monitoring and/or noninvasive or invasive ventilation, as judged by the ED physician, were not included.

\section{Data collected}

The data collected were limited to observations and results that are readily available in all EDs, and addressed the following issues.

\section{Baseline status}

The data collected related to sociodemographic characteristics, occupation, smoking history, known diagnosis of COPD, chronic bronchitis or emphysema, age at first respiratory symptoms, usual severity of dyspnoea using a modified Medical Research Council scale (0: dyspnoea during intensive exercise only; 1 : dyspnoea when climbing two or more flights of stairs; 2: dyspnoea when walking uphill or quickly on level ground; 3: dyspnoea when walking on level ground at the same pace as persons of the same age; 4: dyspnoea when walking at their own pace on level ground; 5: dyspnoea when eating, dressing or preventing the patient leaving home) [24], reported number of emergency visits and hospitalisations during the past 6 months, usual follow-up (general practitioner and/or respiratory physician) and maintenance treatments.

\section{Exacerbation management in the ED}

Data were collected regarding the duration of the exacerbation, treatments and medical visits before arrival in the ED, origin of referral, dyspnoea grade at entry, clinical signs of severity, auscultatory findings, arterial blood gas variables, diagnostic procedures and treatments, and length of stay in the ED.

\section{Exacerbation management following discharge from the ED}

The data collected related to hospitalisation and its setting(s) (general medical ward, respiratory medicine department and ICU) and duration, diagnostic procedures and treatments.

\section{Discharge from hospital}

Data were collected regarding vital status, final diagnosis (confirmed exacerbation of COPD or alternative diagnosis), certain or probable aetiology of the exacerbation, mode of discharge (to home with or without support or to convalescence or nursing home), treatment and planned medical appointments. The diagnosis of COPD exacerbation was considered as confirmed (or rejected) after review by the local coordinating respiratory physician.

\section{Statistical analysis}

Data are presented as mean \pm SD or percentage. The in-hospital outcomes of interest were death and requirement for posthospital support (either convalescence, nursing home or domiciliary support). A two-step analytical plan was applied.

The first step was the exploratory assessment of predictors of death and the need for post-hospital support in the whole population in order to ensure maximal statistical power. Univariate analyses (Chi-squared test for categorical variables and an unpaired t-test or ANOVA for continuous variables) were first performed in order to determine which variables were associated with these outcomes. Then, initial symptoms and signs associated with an increased risk of in-hospital death on univariate analysis were aggregated in a clinical severity index, which was integrated into the subsequent analysis. 
Finally, multivariate analyses were performed; a backward stepwise procedure using a logistic regression model was applied, including the variables that were significant at a $\mathrm{p}$ value of $<0.20$ in the univariate analyses. Variables were eliminated one at a time from the model based on likelihood ratio tests. Variables were eligible for inclusion into the final model if they were significantly associated with in-hospital outcomes, with a p-value of $<0.05$.

The second step aimed to confirm the performance of the proposed group of items as predictors of risk of death. The population sample was randomly split into two groups, a derivation cohort $(n=353)$ and a validation cohort $(n=334)$. In the derivation cohort, a backward stepwise logistic regression procedure was performed as described previously, and used to develop a point-based risk scoring system; the number of points assigned to each risk factor was obtained by dividing each $\beta$ coefficient by the smallest $\beta$ coefficient significantly different from 0 and rounding to the nearest integer. A risk score was assigned to each participant in both the derivation and the validation cohorts by summing the number of points corresponding to each risk factor. Model discrimination was assessed using the c-statistic, which is analogous to the area under the receiver operating characteristic curve [25]. In both

TABLE 1 Characteristics of patients with available data

\begin{tabular}{|c|c|c|}
\hline & Patients n & Data \\
\hline Age yrs & 780 & $72.5 \pm 11.8$ \\
\hline Male sex & 784 & 70.0 \\
\hline Pre-hospital care & 794 & 21.5 \\
\hline Self-referral & 781 & 20.5 \\
\hline Current/ex-smokers & 734 & $30.8 / 49.9$ \\
\hline Cumulative tobacco smoking pack-yrs & 734 & $46.4 \pm 30.0$ \\
\hline $\begin{array}{l}\text { Occupational exposure to gas, } \\
\text { fumes, dusts }\end{array}$ & 721 & 28.3 \\
\hline Known COPD\# & 721 & 84.6 \\
\hline $\begin{array}{l}\text { Age at beginning of exertional } \\
\text { dyspnoea yrs }\end{array}$ & 652 & $53.3 \pm 17.8$ \\
\hline Baseline dyspnoea grade & 701 & \\
\hline $0-1$ & & 22.5 \\
\hline $2-3$ & & 46.2 \\
\hline $4-5$ & & 31.3 \\
\hline Previous lung function test & 748 & 69.9 \\
\hline Usual follow-up & 763 & \\
\hline Respiratory physician & & 40.8 \\
\hline General practitioner & & 34.3 \\
\hline Both & & 16.5 \\
\hline None & & 8.4 \\
\hline Usual maintenance treatment & 767 & \\
\hline$\beta_{2}$-agonists & & 69.6 \\
\hline Anticholinergic agents & & 37.5 \\
\hline Inhaled corticosteroids & & 43.8 \\
\hline Oral corticosteroids & & 13.8 \\
\hline Long-term oxygen therapy & & 23.2 \\
\hline
\end{tabular}

Data are presented as mean \pm SD or percentage. Total number of recruited patients, $n=794$. COPD: chronic obstructive pulmonary disease. ${ }^{\#}$ : including chronic bronchitis and emphysema. the derivation and the validation cohorts, subjects were divided into three groups depending upon the tertile of the score, and mortality rates were compared between groups.

\section{RESULTS}

Among the 113 centres that agreed to participate, 103 (91\%) were active and recruited 794 patients.

\section{Patient characteristics}

Table 1 describes the demographic characteristics of the population and gives details of risk factors and medical history. The proportion of retired patients was $78.6 \%$. In addition, $9.0 \%$ did not work any more due to disability. Among the whole population, $27.1 \%$ received home support and $8.4 \%$ lived in an institution. At least one emergency visit during the previous 6 months was reported by $68.2 \%$ and at least one hospitalisation by $37.6 \%$. Initial clinical presentation, severity index, diagnostic procedures and treatments in the ED

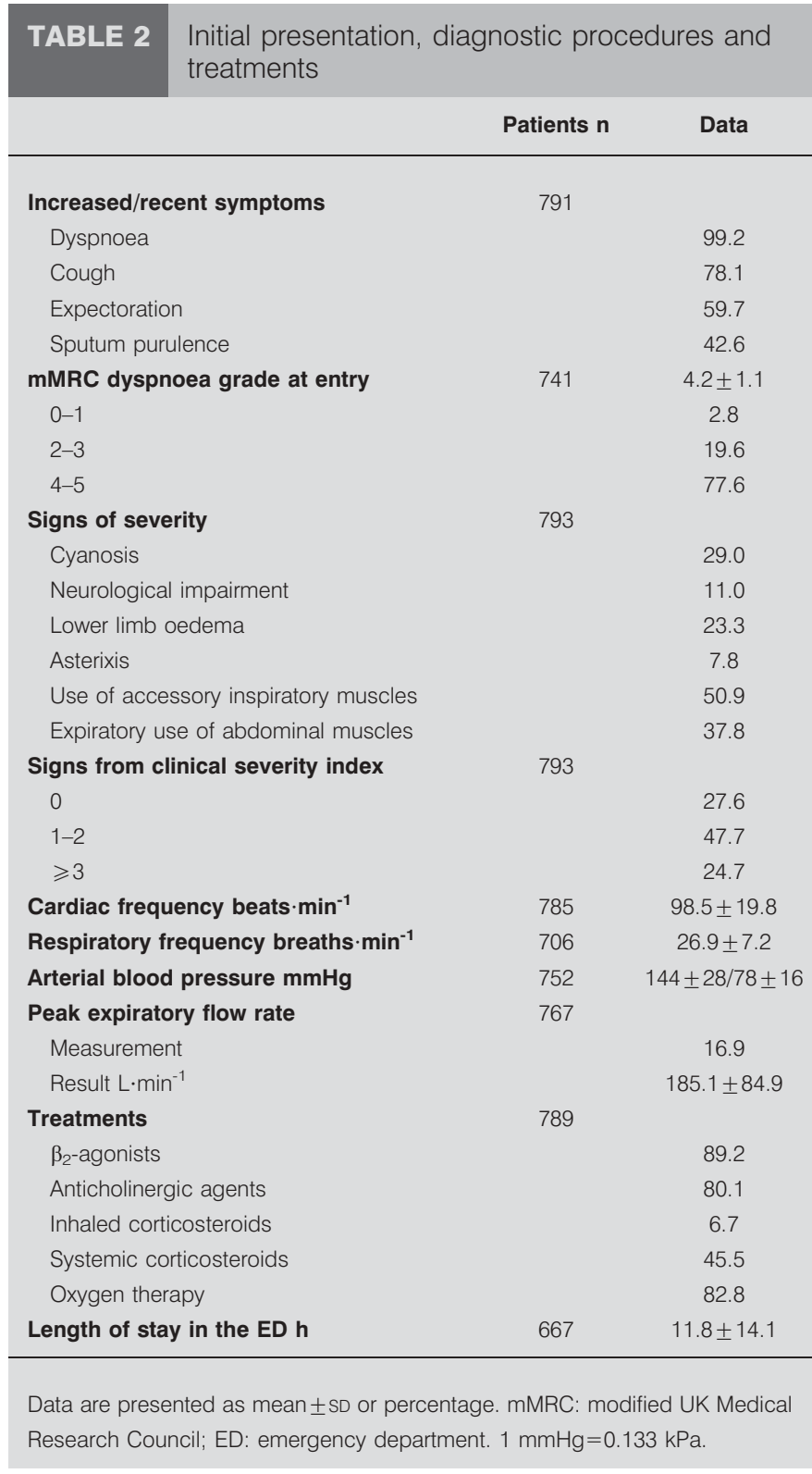


are detailed in table 2 . Wheezing was recorded in $69.3 \%$ and focal crackles in $28.9 \%$. The vast majority $(72.4 \%)$ of patients presented with at least one severity criterion.

Only $84(10.5 \%)$ patients were discharged home from the ED, whereas $533(67.1 \%)$ were hospitalised in a medical ward, 95 $(11.9 \%)$ in an ICU and $62(7.8 \%)$ in another hospital.

Compared to those hospitalised in a medical ward or an ICU, patients discharged home from the ED were younger and less often referred by a doctor; in addition, they showed fewer signs of severity and lower cardiac and respiratory frequencies (data not shown).

At discharge from hospital, the diagnosis of COPD exacerbation was considered as confirmed in 723 (91.6\%) patients. Alternative diagnoses were another respiratory disease in 37 patients, a cardiovascular disease in 19 and another illness in six. When the final diagnosis was a COPD exacerbation, the two main reported aetiologies were bronchial infection in $68.1 \%$ and pneumonia in $14.5 \%$. In $4.7 \%$ of cases, investigators reported that no aetiology was found.

\section{Factors associated with in-hospital death, need for post-hospital support and length of stay}

The in-hospital mortality rate was 7.4\% (59 deaths). At the end of hospital stay, discharge to home without any particular support was possible in 472 (59.5\%) patients, whereas 214 $(26.9 \%)$ required home support or were transferred to convalescence or nursing homes. Since it was not planned to follow patients transferred to other hospitals, 49 (6.2\%) patients were excluded from the analysis. Table 3 shows factors associated with death and need for post-hospital support (at home or in convalescence or nursing homes) on univariate analysis, and table 4 presents the results of multivariate logistic regression analysis when all clinical signs of severity (cyanosis, impaired neurological status, lower limb oedema, asterixis, use of inspiratory accessory muscles and expiratory use of abdominal muscles) were individually integrated into the model. Cardiac and respiratory frequencies did not differ between patients who died and survivors $(98.3 \pm 23.9$ versus $98.5 \pm 19.5$ beats $\cdot \mathrm{min}^{-1}$ and $28.2 \pm 8.2$ versus $26.7 \pm 7.1$ breaths $\cdot \mathrm{min}^{-1}$, respectively). As mentioned in the Statistical analysis section, a three-grade clinical severity index (no severity criteria, one or two severity criteria, and at least thee severity criteria) was constructed on the basis of the number of clinical signs of severity at entry. Using this score, independent prognostic factors on multivariate analysis were age, clinical severity index at entry and baseline dyspnoea grade (table 5). Determinants of the need for post-hospital support on multivariate analysis were sex and risk factors for death (tables 4 and 5).

The need for post-hospital support increased length of stay on univariate analysis (17.3 \pm 13.9 versus $10.5 \pm 7.1$ days; $\mathrm{p}<0.0001$ ), but this effect interacted with the clinical severity index, which was more powerfully associated with length of stay on multivariate analysis (data not shown).

\section{Derivation and validation of the prediction score}

In the derivation cohort, the variables independently associated with risk of death were the same as in the whole population (age, clinical severity index at entry and baseline dyspnoea grade; table 5). The points assigned to each of these three predictors using $\beta$ coefficients were as follows: 1$) 0$ : age $<70$ yrs; 1 : age $\geqslant 70$ yrs; 2 ) 0 : no severity signs; 2 : $1-2$ signs; 3 : $\geqslant 3$ signs; and 3) 0 : baseline dyspnoea grades $0-1$; 1 : grades $2-3$; 2 : grades $4-5$.

TABLE 3 Factors associated with death and need for post-hospital support at discharge on univariate analysis

\begin{tabular}{|c|c|c|c|c|}
\hline & \multicolumn{2}{|c|}{ Death } & \multicolumn{2}{|c|}{ Supported discharge } \\
\hline & Present & Absent & Present & Absent \\
\hline Age yrs & $78.6 \pm 8.1$ & $72.0 \pm 12.0^{*}$ & $78.4 \pm 9.6$ & $68.9 \pm 11.9^{*}$ \\
\hline Self-referral & 5.1 & $21.8^{*}$ & 15.8 & $23.9^{*}$ \\
\hline Previous home support/institutionalisation & 56.9 & $33.8^{*}$ & 60.4 & $21.0^{*}$ \\
\hline Body mass index $\mathrm{kg} \cdot \mathrm{m}^{-2}$ & $24.1 \pm 5.3$ & $25.5 \pm 5.8$ & $24.8 \pm 6.0$ & $25.8 \pm 5.7$ \\
\hline Dyspnoea grade & $4.6 \pm 0.6$ & $4.1 \pm 1.1^{*}$ & $4.4 \pm 1.0$ & $4.0 \pm 1.2^{\star}$ \\
\hline Cyanosis & 50.9 & $27.3^{*}$ & 37.1 & $23.6^{*}$ \\
\hline Neurological impairment & 37.3 & $8.9^{*}$ & 16.9 & $5.3^{*}$ \\
\hline Lower limb oedema & 33.9 & $22.5^{\star}$ & 27.7 & $20.0^{*}$ \\
\hline Asterixis & 17.0 & $7.1^{*}$ & 7.0 & 7.0 \\
\hline Use of inspiratory accessory muscles & 72.9 & $49.2^{*}$ & 60.6 & $42.3^{*}$ \\
\hline Expiratory use of abdominal muscles & 52.5 & $36.7^{\star}$ & 44.6 & $32.9^{*}$ \\
\hline Clinical severity index & $1.5 \pm 0.6$ & $0.9 \pm 0.7^{*}$ & $1.1 \pm 0.7$ & $0.8 \pm 0.7^{\star}$ \\
\hline Respiratory frequency breaths $\cdot \mathrm{min}^{-1}$ & $28.2 \pm 8.2$ & $26.7 \pm 7.1$ & $27.6 \pm 7.2$ & $26.1 \pm 7.0^{\star}$ \\
\hline Cardiac frequency beats $\cdot \mathrm{min}^{-1}$ & $98.3 \pm 23.9$ & $98.5 \pm 19.5$ & $98.2 \pm 20.0$ & $98.3 \pm 19.2$ \\
\hline Hospitalisation during past 6 months & 53.2 & $36.6^{\star}$ & 44.9 & $33.4^{\star}$ \\
\hline Maintenance oral corticosteroids & 22.2 & 13.2 & 14.8 & 12.1 \\
\hline Long-term oxygen therapy & 50.0 & $21.2^{*}$ & 29.1 & $17.4^{\star}$ \\
\hline
\end{tabular}

Data are presented as mean \pm SD or percentage. *: $p<0.05$ versus death/supported discharge 
TABLE 4 Odds ratio for death and need for post-hospital support at discharge on multivariate logistic regression analysis ${ }^{\#}$

\begin{tabular}{lcc} 
& Risk of death & Post-hospital support need \\
\hline $\begin{array}{l}\text { Females versus males } \\
\text { Age } \geqslant \mathbf{7 0} \text { yrs }\end{array}$ C & $2.2(1.4-3.4)$ \\
Clinical signs of severity at entry & $4.5(1.6-12.1)$ & $3.4(2.1-5.5)$ \\
$\quad$ Cyanosis & & $1.6(1.0-2.6)$ \\
$\quad$ Neurological impairment & $1.5(0.7-3.0)$ & $3.3(1.6-6.7)$ \\
Lower limb oedema & $5.1(2.4-10.8)$ & $1.0(0.5-1.5)$ \\
Asterixis & $1.0(0.4-2.0)$ & $0.7(0.3-1.7)$ \\
Use of inspiratory accessory muscles & $1.7(0.6-4.3)$ & $1.6(1.0-2.7)$ \\
Expiratory use of abdominal muscles & $2.6(1.1-6.2)$ & $1.2(0.7-2.0)$ \\
Baseline dyspnoea grade & $0.9(0.4-1.9)$ & 1.0 \\
$0-1$ & & 1.0 \\
$2-3$ & $3.6(0.7-16.5)$ & $1.3(0.7-2.2)$ \\
$4-5$ & $6.5(1.4-29.3)$ & $2.0(1.1-3.6)$ \\
\hline
\end{tabular}

Data are presented as odds ratio (95\% confidence interval). ${ }^{*}$ : when all clinical signs of severity are individually integrated into the model.

Table 6 shows the risk of death in the derivation and validation cohorts dependent upon this score. The prediction characteristics are depicted using the c-statistic and sensitivity and specificity.

Mortality strongly increased with increasing prediction score in both the derivation and the validation cohort. The prediction score showed good discrimination for mortality, with a c-statistic of 0.79 in the derivation cohort and 0.83 in the validation cohort.

\section{DISCUSSION}

The main result of the present real-life study is the identification of simple, immediately accessible and strong predictors of in-hospital death and the need for post-hospital support in

\section{TABLE 5 Independent prognostic factors for death and need for post-hospital support at discharge on multivariate logistic regression analysis ${ }^{\#}$}

\begin{tabular}{lcc} 
& Risk of death & $\begin{array}{r}\text { Post-hospital } \\
\text { support need }\end{array}$ \\
\hline $\begin{array}{l}\text { Females versus males } \\
\text { Age } \geqslant \mathbf{7 0} \text { yrs }\end{array}$ & $3.7(1.3-9.8)$ & $3.4(1.5-3.6)$ \\
Severity index signs at entry & & \\
0 & 1.0 & 1.0 \\
$1-2$ & $5.1(1.1-22.7)$ & $1.6(0.9-2.6)$ \\
$\geqslant 3$ & $13.1(2.9-57.7)$ & $2.9(1.7-5.1)$ \\
Baseline dyspnoea grade & & 1.0 \\
$0-1$ & 1.0 & $1.3(0.7-2.2)$ \\
$2-3$ & $3.3(0.7-14.9)$ & $2.1(1.2-3.6)$ \\
$4-5$ & $5.5(1.2-24.6)$ & \\
\hline
\end{tabular}

Data are presented as odds ratio (95\% confidence interval). For both clinical severity index and dyspnoea grade, a dose-effect relationship is observed. ${ }^{\#}$ : when clinical signs of severity are aggregated in a clinical severity index based on the number of signs present at entry.
COPD patients visiting the ED due to an exacerbation. In addition, the study permitted the derivation and validation of a prediction score based on these items. To the present authors' knowledge, this is the first prospective study to determine outcomes and prognostic factors in patients with COPD exacerbations presenting to the ED. These factors should help in determining: 1) where patients need to be oriented, and 2) for which patients post-hospital support should be prepared early in order to facilitate and hasten discharge; this last point is illustrated by the increased length of stay when post-hospital support was required.

\section{Patient characteristics}

Despite the recruitment through EDs, a relatively high proportion $(41 \%)$ of the patients were followed by a respiratory physician, and 70\% received treatment for COPD. Although $70 \%$ reported undergoing lung function testing or peak expiratory flow rate measurement during past years, only very few of them were able to provide the results of such measurements. In line with these figures, a high proportion $(85 \%)$ of subjects reported knowing that they had COPD

\begin{tabular}{lcc} 
TABLE 6 & $\begin{array}{l}\text { In-hospital mortality in the derivation and } \\
\text { validation cohorts by prediction score tertile }\end{array}$ \\
& Derivation & Validation \\
\hline Subjects $\mathbf{n}$ & 353 & 334 \\
Tertile $\mathbf{1}$ ( $\mathbf{0}$-1 points) & $1.7(2)$ & $0.0(0)$ \\
Tertile $\mathbf{2}(\mathbf{2}-\mathbf{3}$ points) & $4.6(5)$ & $4.8(5)$ \\
Tertile $\mathbf{3}$ (>4 points) & $15.5(19)$ & $12.3(14)$ \\
c-statistic & 0.79 & 0.83 \\
Sensitivity,- & $19 / 26=0.73$ & $14 / 19=0.74$ \\
Specificity & $223 / 327=0.68$ & $215 / 315=0.68$ \\
\hline
\end{tabular}

Data are presented as \% (n), unless otherwise stated. ${ }^{*}$ : tertile 3 versus tertiles 1 plus 2; ": sensitivity (true positive/true positive plus false negative); ${ }^{+}$: specificity (true negative/true negative plus false positive). 
emphysema or chronic bronchitis. This is probably related to the mode of recruitment used in the present study; physicians were asked to include patients with increased dyspnoea (this criterion was indeed satisfied in almost all of the patients) and a diagnosis of certain or probable COPD exacerbation, with no other dominant respiratory disease or cause of acute respiratory failure (e.g. left heart failure or pulmonary embolism). Thus they probably tended to include mainly patients with known COPD, omitting most of the unknown proportion of patients in whom the disease is discovered when the first exacerbation occurs. This would also explain the relatively high level of baseline dyspnoea in most patients and their frequent recourse to healthcare resources in the months preceding the study.

Despite this, the results of lung function tests were known for only a few of the patients, which suggests the need for improving the education of both doctors and patients. Such information could be of interest for the evaluation of the prognosis of an exacerbation and in the decision as to whether and where admission should be considered, but, at present, lung function test results are too infrequently available to be included in a prediction rule, at least in the setting of French hospitals.

Similarly, peak expiratory flow rate was seldom measured, which makes it difficult to interpret its lack of predictive potential. Finally, the conditions of measurement of arterial blood gas levels (i.e. with or without supplemental oxygen) were too heterogeneous to permit any conclusion as to their prognostic value in the real-life ED setting.

\section{Risk factors for in-hospital death}

Although all guidelines list clinical and biological signs of severity that should lead to hospitalisation or admission to the ICU [26-28], only a few studies have addressed this important issue. These studies were reviewed in 2001 in an evidencebased process conducted jointly by the American College of Physicians and the American Society of Internal Medicine [29]. At that time, only 11 studies had been conducted to identify predictors of in-patient mortality, and eight had identified such factors in populations ranging 74-3,050 subjects, recruited with markedly variable inclusion criteria. Of these studies, only five performed multivariate analysis and four were performed in ICU patients alone. The internal validity scores were fairly good but external validity and degree of validation were poor. In the five largest studies with multivariate analysis $(n=322-3,050)$, the independent predictors of in-hospital death were age, acute physiology score, body mass index, functional status before the exacerbation, $\mathrm{Pa}_{\mathrm{a}} \mathrm{O}_{2} /$ inspiratory oxygen fraction ratio, need for mechanical ventilation, serum albumin and sodium levels, and cardiac comorbid conditions. None of these studies provides physicians with a simple prediction rule to aid in the decision as to where a given patient should be managed. In the present study, it was found that three simple clinical criteria were potent predictors of mortality, suggesting that they should be systematically assessed at entry in COPD exacerbations and used to decide where patients should be oriented. These criteria were age, number of clinical signs of severity at entry and baseline dyspnoea grade. Among individual clinical signs of severity, neurological impairment and use of inspiratory accessory muscles were the only factors independently associated with an increased risk of death; however, adding other signs of severity through the aggregated clinical severity index increased the predictive value of the model.

One strength of the present study is that, following identification of predictors of death in the whole study population, two subgroups were randomly constituted to construct a prediction score and assess its validity. As mentioned in the Results section, this score was very easy to calculate, and, when the derivation and validation populations were classified according to score tertile, marked differences in mortality were observed between the two subgroups. In addition, prediction characteristics depicted by the c-statistic, sensitivity and specificity were satisfactory, especially considering the simplicity of the score and particularly the lack of requirement for nonclinical data. Indeed, the c-statistic was higher than that reported by CELLI et al. [30] for the BODE (body mass index, airflow obstruction, dyspnoea and exercise capacity index).

Whether or not such a prediction score might improve patient outcome remains to be determined in a prospective validation study.

\section{Predictors of need for post-hospital support}

Although the need for post-hospital support is clearly an increasingly important clinical and economic issue, the present authors are not aware of any previous studies aimed at identifying the corresponding clinical predictors.

In the present study, factors associated with an increased risk of death were also predictors of the need for post-hospital support, at home or in intermediate care facilities or institutions. This finding is not surprising; if they survive, the most severe patients show an increased level of dependence when they are discharged. Identification of these factors may be useful in helping to reduce length of stay, since patients who need posthospital support as a consequence of increased severity stay longer, which probably relates to two different causes; first, the time taken to recover a health status compatible with discharge may be longer; and, secondly, hospitalisation may be prolonged by difficulties in organising adequate post-hospital support. Such difficulties are likely to become increasingly frequent, considering the increasing age of the population [16]. This will have not only clinical consequences through the increased hospital-related morbidity, quality-of-life impairment and mortality, but also economic consequences since hospital stays account for approximately half of all COPD-related healthcare expenses, with COPD representing the second leading respiratory cause of direct and indirect healthcare costs in the USA and $3.5 \%$ of all healthcare expenses in France $[8,11]$.

Interestingly, the need for post-hospital support was not independently related to any kind of pre-hospital support (home support or residence in a nursing home); the most likely explanation of this is that, in most cases, pre-hospital support was also determined by dyspnoea severity (data not shown).

\section{Limitations of the present study}

As mentioned previously, one main limitation was the lack of lung function and relevant arterial blood gas data, making it impossible to include them in the prediction rule. However, this has to be considered as corresponding to what occurs in 
the real-life setting; thus it does not decrease the value of the identified prognostic factors.

Another limitation is the lack of post-hospital mortality data, which would be mandatory for: 1) validation of the prognostic factors found in the present study and their transformation into admission/discharge criteria; and 2) assessment of the validity of decisions of immediate discharge from the ED. In order to achieve these goals, a large ongoing prospective study includes detailed follow-up at 3 months and assessment of vital status at 3 yrs [31].

Recruitment bias also has to be considered. Indeed, the mean number of patients recruited per centre per month was quite small (approximately three), far lower than that expected during the winter period. As mentioned previously, recruitment was obviously limited to patients with a fairly certain diagnosis of COPD exacerbation at entry. In addition, most centres were active only during short periods of time (14 weeks), and local coordinators checked that cases obviously corresponding to inclusion criteria were not omitted, suggesting that the recruitment was not far from exhaustive during active inclusion periods. Limiting the recruitment period to one winter season ensured that, if some kind of seasonal bias might influence predictors of outcomes, it was homogenously distributed throughout the study period and centres. In addition, since such a bias exists, it corresponds to what happens in real life, and does not compromise the applicability of the results to the period when COPD exacerbations are the greatest cause of concern for clinicians and hospitals.

Finally, the present findings do not apply to COPD cases discovered at the occasion of their first exacerbation since the disease had already been diagnosed in most patients. They also do not apply to patients who require immediate ventilatory support and/or ICU admission when presenting to the ED; inclusion was indeed limited to patients who did not require immediate ventilatory support, as decided by the attending emergency physician. The purpose of this restriction was to limit the heterogeneity of the population and to avoid biasing the results by including a subgroup of patients with very severe exacerbation, which could have induced the identification of factors that might not be applicable to exacerbations of lesser severity.

\section{Conclusions}

The present study provides simple prognostic factors for use in patients with chronic obstructive pulmonary disease exacerbations presenting to the emergency department. The corresponding variables are exclusively clinical and very easy to measure at entry in the real-life context, and represent powerful predictors of the risk of both death and need for post-hospital support. Thus, following prospective validation, they may be useful for clinicians in helping them with: 1) admission and orientation decisions; 2) anticipation of the need for intermediate care facilities or home support; and 3) informing patients and relatives on exacerbation-related short-term risks.

\section{ACKNOWLEDGEMENTS}

The authors would like to thank all of the active investigators who made the present study possible (listed below), and the Société de Pneumologie de Langue Française, SAMU and the
Société Française de Médecine d’Urgence for institutional support.

Members of the Urgence BPCO (COPD Emergency) Scientific Committee (all Paris, France, unless indicated): F. Adnet (SAMU de France, Pontoise, France); M-C. Camus (Boehringer Ingelheim, Reims, France), F. Chabot (Frenchlanguage Society of Respiratory Medicine), J-F. Dessanges (Cochin Hospital), L. Ducros and P. Plaisance (Lariboisière Hospital), P. Gerbeaux (French Society of Emergency Medicine), and S. Salmeron (Saint Joseph Hospital).

Active investigators and participating centres by decreasing number of inclusions (all in France): P.R. Burgel and C. Ginsburg (Cochin Hospital, Paris); F. Carpentiner, N. Chouri Pontarollo and C. Pison, (Grenoble University Hospital, Grenoble); H. Boureaux, J.C. Meurice and J. Rouffineau (Jean Bernard University Hospital, Poitiers); S. Cattaneo, F. Lebargy and X. Schwartz (Maison Blanche University Hospital, Reims); L. Connan and P. Breton (Les Oudairies District Hospital, La Roche-sur-Yon); L.T. Martin Nguyen and T. Mathevon (Gabriel Montpied Hospital, Clermont-Ferrand); G. Kierzek and N. Roche (Hotel Dieu Hospital, Paris); S. Abidi, M. Alazia and D. Vervloet (Sainte Margueritte University Hospital, Marseille); J.F. Bec, J. Boyer and F. Magane (Venne Hospital, Venne); P. Hermant, F. Poler and N. Simon (Poissy/Saint-Germain-enLaye Intermunicipal Hospital, Saint-Germain-en-Laye); F. Faraj and H. Razzouk (Les Acacias Centre, Briançon); R. Escamilla and V. Fassier (Purpan University Hospital, Toulouse); P. Germaud and I. Gueffet (Nantes University Hospital, Nantes); J.R. Barrier, R. Lambert and J.M. Minguet (Draguignan Hospital, Draguignan); D. Andreotti and C. Ehret (Georges Sand Intermunicipal hospital, La-Seyne-sur-Mer); P. Chollet and A. Trinh-Duc (Saint Esprit General Hospital, Agen); J.M. Dot and V. Schoen (Percy Army Training Hospital, Clamart); M. Gabteni, P. Magro and O. Pinco (Trousseau University Hospital, Bretonneau University, Tours); R. Andriamihaja and C. Balleho (Dupuytren University Hospital, Limoges); C. Bernier and S. Jabre (René Pleven General Hospital, Dinan); C. Khouatra and P.J. Souquet (South Lyon Hospital, Pierre-Bénite); M. Bure (Lens Hospital, Lens); J.P. Mathieu and P. Mathieu (Basque coast Hospital, Bayonne); H. Andrianjafy and G. Oliviero (Longjumeau General Hospital); D. Goetghebeur and C. GutGobert (La Cavale Blanche University Hospital, Brest); C. Louerat and P. Nesme (Nord de la Croix Rousse Hospitals, Lyon); P. Dugue and I. Nicolle (Clavary Hospital, Grasse); M. Alitaiga and M. Sandlarz (Denain Hospital, Denain); I. Chary and V. Ioos (Antoine Beclere Hospital, Clamart); F.X. Blanc and B. Doumenc (Bicêtre University Hospital, Le Kremlin-Bicêtre); Y. Courtial and P.J. Souqet (Edouard Herriot Hospital, Lyon); F. Moritz and J.F. Muir (Charles Nicolle University Hospital, Rouen); P. Melandri and M. Mouhssine (Princesse Grace Hospital, Monaco); P. Masson and S. Monnereau (Cholet Hospital, Cholet); P. David, O. Guillemard and C. Vincent (Elbeuf-Louviers Intermunicipal Hospital, Elbeuf); N. Sembach and J. Valcke Brossolette (Georges Pompidou European Hospital, Paris); J. Gonzalez and P. Ray (Pitié Salpetrière Hospital, Paris); J.M. Segalin and B. Lemaire (La Source Hospital, Orleans); P.A. Dufieux and F. Stinhouwer (Victor Provo Hospital, Roubaix); F. Lamotte and X. Roy (Châteauroux Hospital, Châteauroux); G. Newinger and J. Rottner (Mulhouse 
Hospital, Mulhouse); E. Bouvard, S. Dautheville and M. Fartoukh (Tenon Hospital, Paris); P. Cervantes and S. Raymond (Belle Isle Hospital, Metz); M. Mekki and A. Saadi (South Charente Hospitals, Barbezieux); M. Crevat and J.C. Dalphin (Jean Minjoz Hospital, Besançon); L. Boidin and A. Laurencon (Fontenay-le-Comte Hospital, Fontenay-le-Comte); J-M. Beaufils, S. Bossard and E. Pichon (Blois Hospital, Blois); C. Barrier, J-P., Mallet and C. Marty-Enguehard (Saint-Nazaire Hospital, Saint-Nazaire); B-R. Benaicha and V. Lemay (Etampes Hospital, Etampes); T. Pigeanne and Y. Sabbagh (Cote de Lumière Hospital, Les Sables-d'Olonne); L. Djeddou and V. Huot-Maire (Neuilly Hospital, Neuilly); L. du Couedic, C. Jeleff and S. Loutski (Compiègne Hospital, Compiègne); C. Avena, D. Honnart and C. Rabec (Dijon University Hospital, Dijon); A. Cannamela and A. Desira Marie (Roanne Hospital, Roanne); S. Boutin Forzano (North Hospital, Marseille); P. Bonnefoy, J. Chamovillard and B. Dorenlot (Jonzac General Hospital, Jonzac); J.P. Noel and A. Ramadane (Nord Mayenne Hospital, Mayenne); T-D. Hoang, D. Valeyre and M. Wargon (Avicenne Hospital, Bobigny); F. Bandaly and J.C. Yacoub (Vierzon Hospital, Vierzon); P. Ancelin, P. Kidybinski and L. Salman (Layné Hospital, Mont-de-Marsan); C. Verkindre (Germon and Gauthier Hospital, Beuvry); B. Mazet and E. Ratiarison (Angers University Hospital, Angers); B. Guillotel and D. Wingert (Stanislas General Hospital, Wissembourg); P. Dupont and J. Jaudel (Saint Louis Hospital, Saintes); P. Bilbault and A. Chaouat (Hautepierre Hospital, Strasbourg); B. Deborne (Juvisy-sur-Orge Hospital, Juvisy-sur-Orge); S. Bailleux, S. Declemy and F. Macone (Pasteur Hospital, Nice); J-P. Chevalier, S. Hominal and J-M. Hacquier (Annecy Hospital, Annecy); C. de la Vega and H. Sahla (Narbonne General Hospital, Narbonne); J.D. Heyraud and C. Lablanche (Desgenettes Army Training Hospital, Lyon); B. Barreau and M-A. Fischer (Montauban Hospital, Montauban); R.M. Rouquet and N. Vinnemann (Rangueil University Hospital, Toulouse); P. Chanseau, J-M. Marcos and Y. Nehme (Rober Boulin Hospital, Libourne); P. Menager, N. Reinette Lasserre and O. Salmon (South Francilien Hospital, Evry); J.M. Berthezene, A. Bourdin and S. Peyrony (Montpellier University Hospital, Montpellier); J.M. Coursier and C. Quilliec (Antony Private Hospital, Antony); D. Dall'Acqua and D. Wahl (Vichy General Hospital, Vichy); V. Ballestrazzi, L. Boudoux, P. Favier and P.N. Nkwete (Armentières Hospital, Armentières); S. Hernandes (Chateaubriant Hospital, Chateaubriant); C. Khalili and G. Saucier (Jacques Monod Hospital, Flers); C. Legrix and J. Seroussi (Fougères Hospital, Fougères); A. Levy and I. Meyer (Jacques Coeur Hospital, Bourges); T. Devaux and K. Mohn (Laënnec Hospital, Quimper); S. Gibey, D. Gora and V. Reboullet (Emile Pasteur Regional Hospital Centre, Dole); P. Gerbeaux and D. Toro (Hospital of the Conception, Marseille); M. D'Arlhac, P. Gatin and P. Volard (Niort General Hospital, Niort); F. Girard, S. Salmeron and J.S. Wartel (Saint Joseph Hospital, Paris); C. Italiano and D. Levy (Pasteur Hospital, Colmar); and B. Delclaux and A. Hugerot (Troyes General Hospital, Troyes).

\section{REFERENCES}

1 Murray CJ, Lopez AD. Global mortality, disability, and the contribution of risk factors: Global Burden of Disease Study. Lancet 1997; 349: 1436-1442.
2 Almagro P, Calbo E, Ochoa de Echagüen A, et al. Mortality after hospitalization for COPD. Chest 2002; 121: 1441-1448.

3 Groenewegen KH, Schols AM, Wouters EF. Mortality and mortality-related factors after hospitalization for acute exacerbation of COPD. Chest 2003; 124: 459-467.

4 Nevins ML, Epstein SK. Predictors of outcome for patients with COPD requiring invasive mechanical ventilation. Chest 2001; 119: 1840-1849.

5 Patil SP, Krishnan JA, Lechtzin N, Diette GB. In-hospital mortality following acute exacerbations of chronic obstructive pulmonary disease. Arch Intern Med 2003; 163: 1180-1186.

6 Wang Q, Bourbeau J. Outcomes and health-related quality of life following hospitalization for an acute exacerbation of COPD. Respirology 2005; 10: 334-340.

7 Seemungal TA, Donaldson GC, Paul EA, Bestall JC, Jeffries DJ, Wedzicha JA. Effect of exacerbation on quality of life in patients with chronic obstructive pulmonary disease. Am J Respir Crit Care Med 1998; 157: 1418-1422.

8 Detournay B, Pribil C, Fournier M, et al. The SCOPE study: health-care consumption related to patients with chronic obstructive pulmonary disease in France. Value Health 2004; 7: 168-174.

9 Donaldson GC, Seemungal TA, Bhowmik A, Wedzicha JA. Relationship between exacerbation frequency and lung function decline in chronic obstructive pulmonary disease. Thorax 2002; 57: 847-852.

10 Soler-Cataluna JJ, Martinez-Garcia MA, Roman SP, Salcedo E, Navarro M, Ochando R. Severe acute exacerbations and mortality in patients with chronic obstructive pulmonary disease. Thorax 2005; 60: 925-931.

11 Sullivan SD, Ramsey SD, Lee TA. The economic burden of COPD. Chest 2000; 117: Suppl. 2, 5S-9S.

12 Andersson F, Borg S, Jansson SA, et al. The costs of exacerbations in chronic obstructive pulmonary disease (COPD). Respir Med 2002; 96: 700-708.

13 Miravitlles M, Jardim JR, Zitto T, Rodrigues JE, Lopez H. Pharmacoeconomic study of antibiotic therapy for exacerbations of chronic bronchitis and chronic obstructive pulmonary disease in Latin America. Arch Bronconeumol 2003; 39: 549-553.

14 Oostenbrink JB, Rutten-van Molken MP. Resource use and risk factors in high-cost exacerbations of COPD. Respir Med 2004; 98: 883-891.

15 Wouters EF. Economic analysis of the Confronting COPD survey: an overview of results. Respir Med 2003; 97: Suppl. C, S3-S14.

16 Cydulka RK, McFadden ERJ, Emerman CL, Sivinski LD, Pisanelli W, Rimm AA. Patterns of hospitalization in elderly patients with asthma and chronic obstructive pulmonary disease. Am J Respir Crit Care Med. 1997; 156: 1807-1812.

17 Rieves RD, Bass D, Carter RR, Griffith JE, Norman JR. Severe COPD and acute respiratory failure. Correlates for survival at the time of tracheal intubation. Chest 1993; 104: 854-860.

18 Gunen H, Hacievliyagil SS, Kosar F, et al. Factors affecting survival of hospitalised patients with COPD. Eur Respir J 2005; 26: 234-241.

19 Pinckney RG, O'Brien R, Piccirillo JF, Littenberg B. Evaluation of co-morbidity indices in patients admitted 
for chronic obstructive pulmonary disease. Monaldi Arch Chest Dis 2004; 61: 209-212.

20 Yang S, Tan KL, Devanand A, Fook-Chong S, Eng P. Acute exacerbation of COPD requiring admission to the intensive care unit. Respirology 2004; 9: 543-549.

21 Seneff MG, Wagner DP, Wagner RP, Zimmerman JE, Knaus WA. Hospital and 1-year survival of patients admitted to intensive care units with acute exacerbation of chronic obstructive pulmonary disease. JAMA 1995; 274: 1852-1857.

22 Tan WC. Factors associated with outcomes of acute exacerbations of chronic obstructive pulmonary disease. COPD 2004; 1: 225-247.

23 Roche N, Zureik M, Neukirch F, Perrotin D. L'étude "Urgence-BPCO 2003" : une description de la prise en charge hospitalière des exacerbations de BPCO. [The "COPD emergency 2003" study: a description of the hospital management of exacerbations of COPD.]. Rev Mal Respir 2004; 21: 117-122.

24 Mahler DA, Harver A. A factor analysis of dyspnea ratings, respiratory muscle strength, and lung function in patients with chronic obstructive pulmonary disease. Am Rev Respir Dis 1992; 145: 467-470.

25 Hanley JA, McNeil BJ. The meaning and use of the area under a receiver operating characteristic (ROC) curve. Radiology 1982; 143: 29-36.
26 Celli BR, Macnee W. Standards for the diagnosis and treatment of patients with COPD: a summary of the ATS/ ERS position paper. Eur Respir J 2004; 23: 932-946.

27 National Heart, Lung and Blood Institute, National Institutes of Health, World Health Organization. Global Initiative for Chronic Obstructive Lung Disease. Global Strategy for the Diagnosis, Management and Prevention of Chronic Obstructive Lung Disease. 2006. www.goldcopd. com/Guidelineitem.asp? $11=2 \& 12=1 \&$ intID $=989$ Date last accessed: August 1, 2008. Date last updated: January 2008.

28 Société de Pneumologie de Langue Française. Recommandations pour la prise en charge de la bronchopneumopathie chronique obstructive. [Guidelines for the clinical management of COPD.]. Rev Mal Respir 2003; 20: 294-329.

29 Snow V, Lascher S, Mottur-Pilson C. The evidence base for management of acute exacerbations of COPD - clinical practice guideline, part 1 . Chest 2001; 119: 1185-1189.

30 Celli BR, Cote CG, Marin JM, et al. The body-mass index, airflow obstruction, dyspnea, and exercise capacity index in chronic obstructive pulmonary disease. $N$ Engl J Med 2004; 350: 1005-1012.

31 Piquet J, Maurer C, Barbieux H, et al. [Acute exacerbations of COPD admitted to hospital: predictive factors of 3 year mortality.]. Rev Mal Respir 2007; 24: 909-916. 